\title{
An alternative telomerase RNA in Arabidopsis modulates enzyme activity in response to DNA damage
}

\author{
Catherine Cifuentes-Rojas, ${ }^{1}$ Andrew D.L. Nelson, ${ }^{2}$ Kara A. Boltz, Kalpana Kannan, ${ }^{3}$ Xintao She, \\ and Dorothy E. Shippen ${ }^{4}$
}

Department of Biochemistry and Biophysics, Texas A\&M University, College Station, Texas 77843, USA

Telomerase replenishes telomere tracts by reiteratively copying its RNA template, TER. Unlike other model organisms, Arabidopsis thaliana harbors two divergent TER genes. However, only TER1 is required for telomere maintenance. Here we examine the function of TER2. We show that TER2 is spliced and its $3^{\prime}$ end is truncated in vivo to generate a third TER isoform, TER2s. TERT preferentially associates with TER2 > TER1 > TER2s. Moreover, TER2 and TER2 ${ }_{S}$ assemble with Ku and POT1b (protection of telomeres), forming RNP (ribonucleoprotein) complexes distinct from TER1 RNP. Plants null for TER 2 display increased telomerase enzyme activity, while TER2 overexpression inhibits telomere synthesis from TER1 and leads to telomere shortening. These findings argue that TER2 negatively regulates telomerase by sequestering TERT in a nonproductive RNP complex. Introduction of DNA double-strand breaks by zeocin leads to an immediate and specific spike in TER2 and a concomitant decrease in telomerase enzyme activity. This response is not triggered by replication stress or telomere dysfunction and is abrogated in ter2 mutants. We conclude that Arabidopsis telomerase is modulated by TER2, a novel DNA damageinduced noncoding RNA that works in concert with the canonical TER to promote genome integrity.

[Keywords: telomere; noncoding RNA; TRAP assay; ribonucleoprotein; POT1]

Supplemental material is available for this article.

Received August 13, 2012; revised version accepted October 5, 2012.

Chromosomes must be capped with an ample reserve of telomeric DNA to ensure genome stability. The telomerase reverse transcriptase facilitates telomere homeostasis using its catalytic subunit, TERT, to reiteratively copy the internal RNA template TER, thereby replenishing terminal sequences lost during DNA replication. Telomerase is a highly regulated enzyme; its action is largely confined to, and essential for, self-renewing cell populations. Inappropriate telomerase expression promotes tumorigenesis, while insufficient enzyme activity triggers genome instability and stem cell-related disease (Artandi and DePinho 2010). Consequently, sophisticated mechanisms have evolved to modulate telomerase activity.

Although TERT is a highly conserved constituent of telomerase, TER subunits have diverged dramatically in length and nucleotide sequence (Egan and Collins 2012). Nevertheless, phylogenetic and mutational analyses

Present addresses: ${ }^{1}$ Department of Molecular Biology, Massachusetts General Hospital, 185 Cambridge St., Boston, MA 02114, USA; ${ }^{2}$ School of Plant Sciences, University of Arizona, Tucson, AZ 85721, USA; ${ }^{3}$ Department of Pathology, Baylor College of Medicine, One Baylor Plaza, S234, BCM315, Houston, TX 77030, USA.

${ }^{4}$ Corresponding author

E-mail dshippen@tamu.edu

Article published online ahead of print. Article and publication date are online at http://www.genesdev.org/cgi/doi/10.1101/gad.202960.112. reveal functionally conserved elements, including a single-strand templating domain typically corresponding to one and a half telomeric repeats flanked by a $5^{\prime}$ boundary element and a 3' pseudoknot domain. Human telomerase activity can be reconstituted with only the TER pseudoknot/template region and the CR4/CR5 trans-activation domain (Tesmer et al. 1999; Mitchell and Collins 2000). Similarly, yeast and Arabidopsis telomerase activity is supported by a "mini $\mathrm{T}$ " version of TER consisting of $\sim 150$ nucleotides (nt) (Zappulla et al. 2005; Cifuentes-Rojas et al. 2011). Thus, TER is postulated to act as a scaffold for telomerase accessory proteins. Such proteins facilitate ribonucleoprotein (RNP) biogenesis, trafficking, and interactions with the chromosome terminus (Egan and Collins 2012). Vertebrate TERs associate with the RNP maturation complex dyskerin, while budding yeast TER assembles with Sm proteins and is processed as an snRNA. Notably, biogenesis of Schizosaccharomyces pombe TER involves a novel 3' end "slicing" mechanism (Leonardi et al. 2008) that requires the sequential binding of SM and Lsm complexes (Tang et al. 2012). Other TER-binding factors include the KU70/80 heterodimer, which in Saccharomyces cerevisiae acts as a positive regulator of telomerase (Boulton and Jackson 1998). 
Much of what is known concerning telomerase regulation centers on enzyme activation. In human cells, transcriptional regulation of the catalytic subunit TERT is a major point of control, although alternative splicing, post-translational modification, and intracellular trafficking of TERT also contribute to enzyme regulation (Cifuentes-Rojas and Shippen 2012). Increased expression of TER is correlated with enzyme activation in some settings, but evidence that TER plays a significant role in modulating enzyme activity is currently lacking.

In conjunction with tight regulation of telomerase activity at natural chromosome ends, the enzyme must also be strictly prohibited from acting at double-strand breaks (DSBs) to ensure faithful repair and to prevent "chromosome healing" by de novo telomere formation (DNTF). DNTF is a perilous endeavor due to loss of flanking DNA, and in humans it is associated with genetic disorders such as $\alpha$-thalassemia, mental retardation, and cancer (Flint et al. 1994; Hanish et al. 1994). A variety of different strategies evolved to curtail telomerase interaction with DSBs. As part of the DNA damage response (DDR) in yeast, the telomere protein Cdc13 is phosphorylated by Mec1 (ATR), blocking its association with a DSB (Pennock et al. 2001) and the subsequent recruitment of telomerase (Zhang and Durocher 2010). Mec1 also stimulates the phosphorylation-dependent activation of Pif1 (Makovets and Blackburn 2009), a helicase that evicts telomerase particles engaged in synthesis by unwinding the TER-DNA hybrid (Boule et al. 2005). While similar mechanisms have not been described for multicellular eukaryotes, human TERT is phosphorylated by c-Abl in response to ionizing radiation, a modification that is associated with telomerase inhibition (Kharbanda et al. 2000). Ionizing radiation also triggers the transient sequestration of hTERT in the nucleolus, a response that would temporarily impede DNTF (Wong et al. 2002).

Plants control telomerase activity in a fashion similar to animals, repressing the enzyme in leaves where cell division is waning and increasing expression in seedlings, flowers, and other cells with high proliferation potential (Fitzgerald et al. 1999). As in vertebrates, core components of Arabidopsis thaliana telomerase include TERT (Fitzgerald et al. 1999; Cifuentes-Rojas et al. 2011) and likely dyskerin (Kannan et al. 2008). However, A. thaliana is unique among model organisms studied to date, as it encodes two telomerase RNA subunits: TER1 (748 nt) and TER2 (784 nt) (Cifuentes-Rojas et al. 2011). TER1 and TER2 share a 220-nt highly conserved domain that in TER2 is divided into two segments interrupted by $529 \mathrm{nt}$ of intervening sequence. Both TER 1 and TER2 assemble with TERT to form an active enzyme in vitro, but only TER1 is required for telomere maintenance in vivo (Cifuentes-Rojas et al. 2011). A null mutation in the template domain of TER2 does not perturb telomere length homeostasis under standard growth conditions (Cifuentes-Rojas et al. 2011), and hence the function of this RNA has been unclear.

Another key component of the TER1 RNP is POT1a (protection of telomeres), one of three POT1 paralogs in A. thaliana (Shakirov et al. 2005; Surovtseva et al. 2007;
A Nelson and D Shippen, unpubl.). Vertebrate POT1 binds the $3^{\prime}$ overhang on the chromosome terminus, thereby prohibiting DDR and the inappropriate enzymatic reactions triggered by it (Baumann and Price 2010). In contrast, Arabidopsis POT1a is a telomerase RNP constituent that contacts TER 1 and acts in the same genetic pathway as TERT for telomere maintenance (Surovtseva et al. 2007; Cifuentes-Rojas et al. 2011). Overexpression studies suggest that POT1b contributes to telomere integrity (Shakirov et al. 2005), and yet, like POT1a, POT1b does not interact with telomeric DNA in vitro (Shakirov et al. 2009). In addition, POT1b does not bind TER1 (Cifuentes-Rojas et al. 2011). Thus, TER2 and POT1b do not promote the canonical role of telomerase in telomere maintenance.

Here we describe a new regulatory pathway for telomerase wherein TER2 inhibits telomere synthesis by TER1. Specifically, we show that Arabidopsis harbors three different isoforms of TER, including a processed RNA derived from TER2. We demonstrate that telomerase activity is elevated in the absence of TER2 and decreased when TER2 is overexpressed. Additionally, we show that TER 2 and TER $2_{S}$ assemble with POT1b and $\mathrm{Ku}$ into alternative RNP complexes that cannot sustain telomere repeats on chromosome ends. Finally, we demonstrate that telomerase activity is repressed in response to DSBs, and this regulation is dependent on TER2. We conclude that TER2 is a novel component of the DDR that modulates telomerase activity.

\section{Results}

A third TER isoform is generated by splicing and $3^{\prime}$ end cleavage of TER2

We discovered a third isoform of $A$. thaliana TER in experiments designed to examine the expression profile of TER1 and TER2. Primer extension with an oligonucleotide complementary to a region conserved in both TER 1 and TER2 (CR2) (Fig. 1A) generated the predicted products as well as a smaller species of $\sim 220 \mathrm{nt}$ (Fig. 1B). This new RNA was amplified by end-point RT-PCR (Supplemental Fig. S1) and was also detected by Northern blot analysis in both flowers and cell culture (Fig. 1C), ruling out artifactual PCR amplification or bypass reverse transcription. For reasons discussed below, the new RNA was termed TER $2_{S}$.

Cloning and sequencing revealed that TER $2_{S}$ is identical to TER2 with two exceptions. First, TER $2_{S}$ lacks the 529-nt segment in TER2 that interrupts the two highly conserved regions shared with TER1 (Fig. 1A). In TER2 $2_{S}$ CR1 and CR2 are precisely joined (Fig. 1D) to create a contiguous $220-n t$ stretch with $85 \%$ identity to the corresponding region in TER1. The 11-nt telomere template sequence is retained in TER $2_{\mathrm{S}}$. BLAST searches failed to identify a locus in the $A$. thaliana genome that could encode TER $2_{S}$, indicating that this RNA is a processed form of TER2. Second, 3' linker ligation followed by RT-PCR showed that TER $2_{S}$ is truncated relative to TER2, resulting in elimination of a nonconserved region 
A

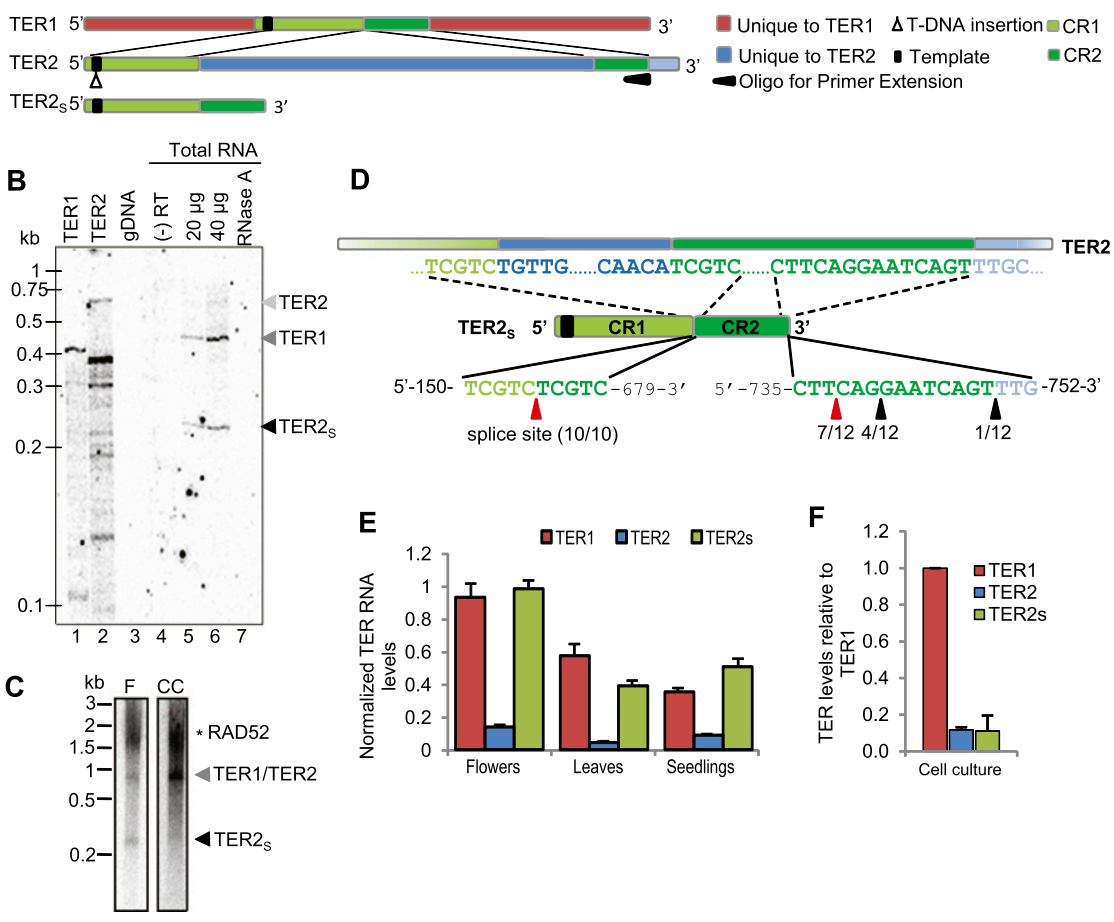

Figure 1. A. thaliana contains three TER isoforms. (A) Diagram of the three TER isoforms in Arabidopsis. (B) Primer extension results of total cellular RNA from cell culture using a primer complementary to a region in CR2 (filled arrow in A). (Lane 1) In vitro transcribed TER1. (Lane 2) In vitro transcribed TER2. (Lane 3) Forty micrograms of genomic DNA (gDNA). (Lane 4) Control with $40 \mu \mathrm{g}$ of total RNA in the absence of reverse transcriptase. (Lane 5) Twenty micrograms of total RNA. (Lane 6) Forty micrograms of total RNA. (Lane 7) Forty micrograms of total RNA pretreated with RNase A. MW markers are indicated on the left. $(C)$ Northern blot results for using $60 \mu \mathrm{g}$ of total cellular RNA from flowers or cell culture. The blot was hybridized using a radiolabeled probe complementary to CR2. (Black arrowhead) TER2 ${ }_{\text {S; }}$ (gray arrowhead) TER1/TER2. (*) RAD52 mRNA is also detected because TER1 CR1 is embedded in the $5^{\prime}$ region of this gene (Samach et al. 2011). (D) Sequence analysis of the splice junction and $3^{\prime}$ end of TER $2_{S}$ isolated from flowers. The nucleotide number refers to the corresponding nucleotide within TER2. The number of clones recovered with each sequence is indicated below the vertical arrowheads. qRT-PCR results showing relative levels of TER isoforms in different plant tissues $(E)$ and Arabidopsis cell culture $(F)$ are shown. Values in $E$ are relative to TER1 in flowers. Error bars represent SD. $n>5$ for all data points.

just downstream from CR2 (Fig. 1A). Unlike the internal splice junction, the $3^{\prime}$ terminus of TER $2_{S}$ is somewhat heterogeneous: Three different $3^{\prime}$ ends were mapped (Fig. 1D). Notably, the length of TER $2_{S}$ differed slightly in flowers versus cell culture (Fig. 1C). Whether the size difference is a reflection of alternative $3^{\prime}$ end formation is unknown.

To assess the steady-state levels of the TER RNAs during plant development, quantitative RT-PCR (qRTPCR) was performed (Fig. 1E). The steady-state levels of TER1 and TER2 $\mathrm{S}$ were nearly equivalent, peaking in flowers and declining in nonreproductive tissues (Fig. 1E). A somewhat different profile of TER expression was observed in Arabidopsis cell culture. In this setting, TER1 levels were significantly higher than either TER2 or TER $2_{S}$, and the latter RNAs were essentially equivalent (Fig. 1F). The biological basis for this variation in TER abundance is currently unclear.

\section{Neither TER2 nor TER2 efficiently incorporates telomere repeats onto chromosome ends}

TER2 and an RNA construct corresponding to TER2 $\mathrm{S}$ (TER2-B) assemble with TERT to reconstitute telomerase activity in vitro (Cifuentes-Rojas et al. 2011). Therefore, we asked whether TER2 or TER $2_{S}$ directs telomere repeat synthesis in vivo using site-directed mutagenesis. A similar strategy taken with TER1 demonstrated that this RNA acts as a highly efficient telomerase template in vivo (Cifuentes-Rojas et al. 2011). We mutated the templating domain in TER2 from 5'-CUAAACCCUA-3' to 5'-CUAGUACCUA-3' (TER2 ${ }_{\mathrm{RSA}}$ ). This mutation, which will direct synthesis of TAGGTAC instead of canonical TAGGGTT repeats, allows us to distinguish synthesis from TER2 versus TER1 in vivo. In vitro reconstitution with recombinant TERT confirmed that TER2 $2_{\text {RSA }}$ supports telomere repeat incorporation (Supplemental Fig. S2A), and thus the mutation did not significantly alter TER2 function. TER $2_{\text {RSA }}$ was then placed under the control of the powerful cauliflower mosaic virus (CaMV) 35S promoter and transformed into plants null for TER2, ter2-1 (Cifuentes-Rojas et al. 2011). As expected, TER1 levels were wild type in these lines (Fig. 2A), while TER $2_{\text {RSA }}$ was $\sim 30$-fold higher than TER 2 in wild type. In contrast, TER $2_{\text {S-RSA }}$ increased by only $\sim 2.5$-fold, implying that the generation of TER $2_{S}$ is regulated in vivo. TRAP assays were performed on nuclear extracts from the transformants using primers designed to detect RSA-type repeats. Telomerase activity was detected with these primers (Fig. 2B), indicating that TER2 $2_{\mathrm{RSA}}$ and/or TER2 $2_{\mathrm{S}-\mathrm{RSA}}$ assemble into enzymatically active RNP complexes in vivo. In addition, $35 S:: T E R 2_{R S A}$ mutants were phenotypically wild type, indicating that the mutant telomere repeat either had not been efficiently incorporated onto chromosome ends or had no effect on telomere stability.

Primer extension telomere repeat amplification (PETRA) was used to assay for RSA-type repeats on chromosome ends. As expected, PETRA reactions with wild-type primers yielded PCR products in both transformed and untransformed lines (Fig. 2C, left panel). In addition, the 
A

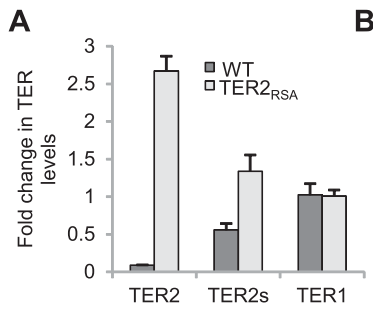

D

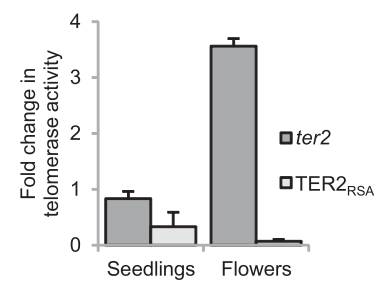

B

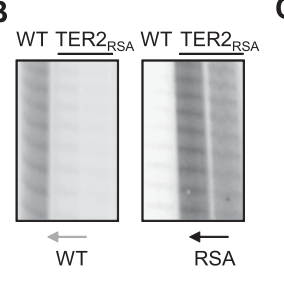

E

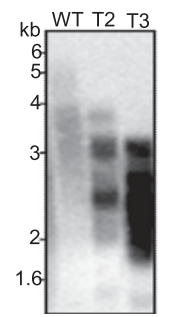

C

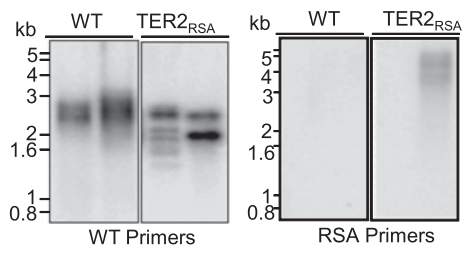

$\mathbf{F}$

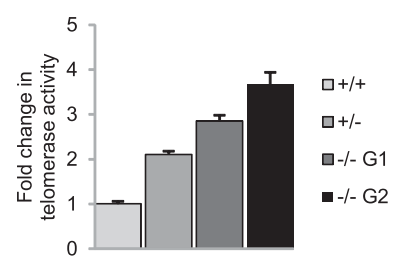

Figure 2. TER2 assembles into an active enzyme in vivo but cannot maintain telomere repeats on chromosome ends. $(A)$ qRT-PCR results for TER levels in 35S:: TER $2_{\text {RSA }}$ transformed seedlings. RNA levels are relative to TER1 in wild-type seedlings. (B) TRAP results for TER2 $2_{\text {RSA }}$ transformants. Conventional TRAP was performed using a wild-type reverse primer (left panel) or a primer specific for the RSA repeat (right panel). Extracts from wild-type seedlings (WT lanes) served as a positive or negative control, respectively. (C) PETRA results for $35 \mathrm{~S}:: \mathrm{TER} 2_{\mathrm{RSA}}$ transformants. Reactions were conducted with a reverse primer complementary to wild-type telomere repeats or RSA mutant repeats as shown. Results for two independent wild-type plants and two 35S::TER2 $2_{\text {RSA }}$ transformants with each primer are shown. $(D)$ Q-TRAP results for the flowers and seedlings of $35 \mathrm{~S}:: \mathrm{TER} 2_{\mathrm{RSA}}$ transformants. Reactions used a reverse primer complementary to the wild-type repeat as in $B$. Activity is shown relative to wild-type tissue. (E) TRF analysis of the second (T2) and third (T3) generations of 35S::TER2 $\mathrm{RSA}$ transformants. $(F)$ Q-TRAP results for wild type, ter2 heterozygotes, and G1 and G2 ter2 homozygous-null mutants. Values were normalized to telomerase activity in wild-type plants. In $D$ and $F, n \geq 3$.

PETRA- $\mathrm{T}_{\mathrm{RSA}}$ primer failed to generate products for wildtype plants (Fig. 2C, right panel). Despite overexpression of TER2 $2_{\text {RSA }}$, faint products could be detected in reactions with PETRA-T $T_{\text {RSA }}$ for only one of the two TER2 $2_{\text {RSA }}$ mutant lines (Fig. 2C, right panel). Because of the low abundance of these products, we cloned and sequenced PETRA products from TER $2_{\mathrm{RSA}}$ transformants that were amplified using wild-type PETRA primers. Sequence analysis failed to show any of the predicted TAGGTAC (RSA-type) repeats. However, in seven of 50 clones sequenced, one or more nucleotide misincorporation events were detected (Supplemental Fig. S2B). In contrast to the results with TER2 $2_{\mathrm{RSA}}$, a significant portion of the telomere tracts cloned from plants expressing a mutant TER1 (TER1 $1_{\text {CC }}$ ) carried the expected mutant telomere repeat (65 of 150 ), even though TER $1_{\mathrm{CC}}$ was competing with endogenous wild-type TER1 in this earlier experiment (Cifuentes-Rojas et al. 2011). Although we cannot exclude the possibility of selection against mutant repeats generated by TER $2_{\mathrm{RSA}}$, in other organisms, incorporation of a toxic telomere repeat sequence leads to profound telomere instability (Yu et al. 1990). This was not observed. These findings and the genetic data presented below argue that neither TER2 nor TER $2_{S}$ efficiently directs telomere repeat incorporation in vivo. Instead, we propose that the low-level aberrant repeat incorporation observed is a consequence of inappropriate TER2 engagement with the telomeres and TER1 inhibition (see below).

\section{TER2 negatively regulates TER1-directed telomerase activity in vivo}

Quantitative TRAP (Q-TRAP) assays unexpectedly revealed that endogenous telomerase activity was reduced by fourfold in $35 \mathrm{~S}::$ TER $2_{\mathrm{RSA}}$ seedlings and $\sim 17$ fold in flowers compared with untransformed ter2-1 controls (Fig. 2D). Because this reduction correlates with expression of TER $2_{\text {RSA }}$ and not TER $2_{\mathrm{S}-\mathrm{RSA}}$ (Fig. $2 \mathrm{~A}$ ), the data argue that increased TER2 is responsible for decreased telomerase activity. Furthermore, because $35 \mathrm{~S}:$ : $T E R 2_{R S A}$ transformants harbor a null mutation at the endogenous TER2 locus, telomere repeat synthesis must be suppressed from the TER1 RNP. Although no change in telomere length was observed in first-generation transformants (T1), terminal restriction fragment (TRF) analysis revealed markedly shorter tracts in the second and third generations (T2 and T3) (Fig. 2E), consistent with limiting telomerase activity in vivo.

If TER2 is a negative regulator of telomerase, enzyme activity should be elevated in plants null for TER2. Indeed, telomerase activity increased 2.1-fold in firstgeneration (G1) ter2-1 heterozygotes, 2.8-fold in G1 ter2-1 homozygotes, and 3.7-fold in second-generation (G2) ter2-1 homozygotes (Fig. 2F). Telomerase activity was confined to organs where the enzyme is normally expressed; activity was low or undetectable in leaves (Supplemental Fig. S2C). Consistent with previous results showing that increased telomerase activity does not trigger telomere elongation in A. thaliana (Ren et al. 2004), telomeres were in the wild-type range in ter2-1 mutants and their offspring (Supplemental Fig. S2D). Taken together, the data indicate that TER2 inhibits the enzymatic activity of TER1 RNP but does not contribute to telomere length maintenance under standard growth conditions.

\section{TER2 and TER2 $2_{S}$ assemble into RNP complexes in vivo}

To investigate how TER2 regulates TER1 RNP, we examined TER2-protein interactions, beginning with TERT. TERT was expressed in rabbit reticulocyte lysate (RRL), and a double-filter binding assay was performed with radiolabeled in vitro transcribed, ${ }^{32} \mathrm{P}$-labeled TER1, TER2, or TER2s. As expected, none of the TERs bound 
TRFL4 (Fig. 3A), a double-stranded telomeric DNA-binding protein (Karamysheva et al. 2004). Binding assays with TERT showed a higher affinity for TER2 over TER1, while TERT binding to TER2 $\mathrm{S}$ was not detected under these conditions (Fig. 3A,B; Supplemental Fig. S3A). We next examined TERT-TER interactions in vivo by coimmunoprecipitation (co-IP) using anti-TERT antibody on 5-d-old $A$. thaliana cell culture extracts followed by qRT-PCR (Fig. 3C; Supplemental Fig. S3B). As expected, none of the TER isoforms was detected in histone $\mathrm{H} 3$ or preimmune immunoprecipitation control reactions (Fig. $3 C)$. Although TER 1 is $\sim 10$-fold more abundant than TER2 in cell culture (Fig. 1F), TER2 was overrepresented in the TERT immunoprecipitation compared with TER1 and enriched by approximately sevenfold relative to the input (Fig. 3C). Notably, TER2 S was barely detected in the TERT immunoprecipitation. These findings are consistent with in vitro binding data indicating that TERT preferentially binds TER $2>$ TER $1>$ TER $2_{S}$.

A candidate approach was used to identify other pro-

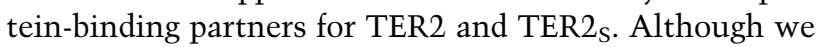
previously failed to detect in vitro binding of $\mathrm{Ku}$ with TER1 (Cifuentes-Rojas et al. 2011), filter binding and coIP followed by RT-PCR revealed an interaction between TER2 and Ku but not TRFL4 (Fig. 3D,F; Supplemental Fig. S3D). Another putative TER2-binding protein is POT1b. POT1b displayed the opposite affinity of its POTla paralog (Cifuentes-Rojas et al. 2011), as it preferentially bound TER2 over TER1 (Fig. 3D,E; Supplemental Fig. S3D). Gel shift analysis confirmed the interaction between TER2 and POT1b and demonstrated its specificity (Fig. 3E). Finally, filter binding showed TER2 ${ }_{S}$ interactions with POT1b and $\mathrm{Ku}$ and a potential weak interaction with POT1a (Fig. 3D).

To further evaluate TER2/TER $2_{S}$ interactions in vivo, immunoprecipitation was performed with dyskerin, POT1a, POT1b, and Ku70 antibodies. qRT-PCR showed that like TER1 (Cifuentes-Rojas et al. 2011), TER2 is associated with dyskerin (Supplemental Fig. S3C). TER $2_{\mathrm{S}}$, on the other hand, was not enriched in the dyskerin immunoprecipitation, consistent with the presence of a putative H/ACA box at the $3^{\prime}$ terminus of TER2 that is eliminated upon $3^{\prime}$ end cleavage of TER2. In the POT1b immunoprecipitation, TER $2_{S}$ was enriched by 10 -fold relative to input. However, only trace amounts of TER 2 were detected (Fig. 3C), indicating that POT1b has a strong preference for TER $2_{S}$ in vivo. Neither TER2 nor TER2 $\mathrm{S}$ was detected in an immunoprecipitation reaction with POT1a antibody (Fig. 3C). Finally, although both TER2 and TER2 $2_{S}$ were associated with $\mathrm{Ku}, \mathrm{TER} 2$ was enriched by eightfold in the immunoprecipitation, and TER $2_{S}$ was enriched by only twofold. Altogether, the co-IP data indicate that TER2 and TER2 ${ }_{S}$ assemble into RNP complexes that are distinct from TER1 RNP. TER2 associates with TERT, dyskerin, Ku, and, to a lesser extent, POT1b, while TER $2_{S}$ accumulates in
A
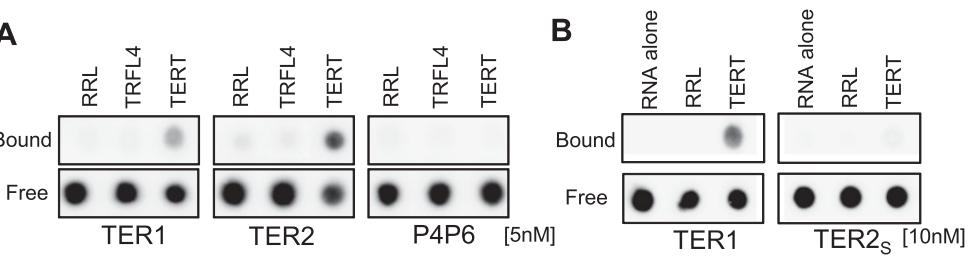

C

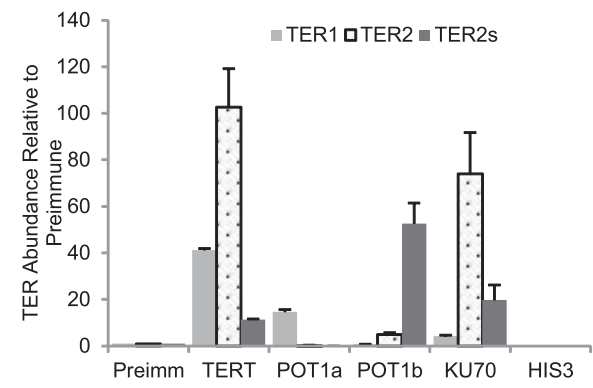

E

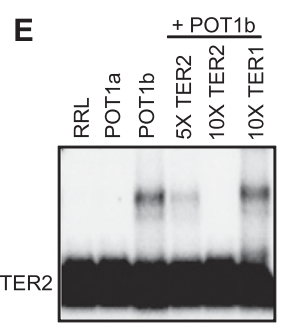

D
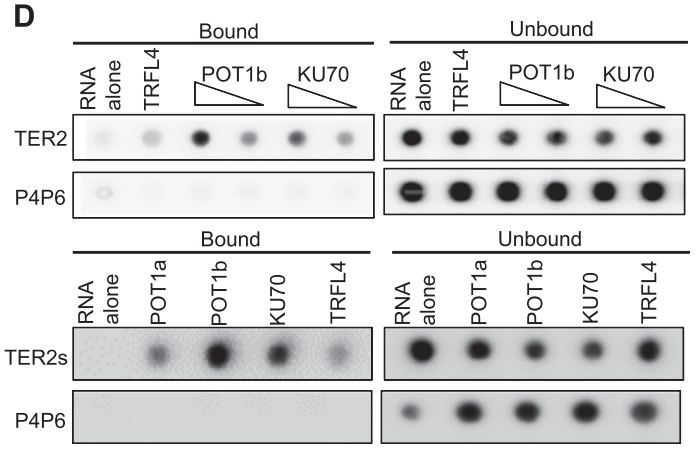

$\mathbf{F}$

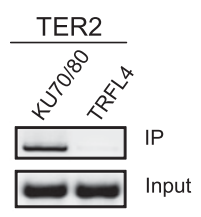

Figure 3. The three TER isoforms assemble into distinct RNP complexes. In vitro filter-binding assay results for TERT with TER1, TER2, and TER2 $2_{S}$ are shown in $A$ and $B$. RRL-expressed TERT was incubated with $5 \mathrm{nM}$ or $10 \mathrm{nM}$ radiolabeled RNA as indicated. TRFL4 protein and P4P6 RNA served as negative controls. $(C)$ Identification of TER-associated proteins in vivo. Arabidopsis cell culture was subjected to immunoprecipitation using the indicated antibodies, and relative TER levels were monitored by qRT-PCR. Anti-histone H3 antibody was used as a negative control. RNA levels were normalized relative to actin-2 and compared with preimmune. $(D)$ In vitro filter-binding results for TER2 and TER 2 S with the recombinant proteins indicated. Assays were conducted with $1 \mathrm{nM}$ labeled RNA. For POT1b and $\mathrm{Ku} 70,5 \mu \mathrm{L}$ or $7 \mu \mathrm{L}$ of programmed RRL was used. (E) Results of TER2 electrophoretic mobility shift assays with recombinant POT1a and POT1b. Competition was performed with cold RNA as indicated. $(F)$ In vitro immunoprecipitation RT-PCR analysis using TER2 and recombinant $\mathrm{Ku} 70 / 80$ and or TRFL4. 
a subcomplex primarily containing POT1b and, to a lesser extent, Ku.

\section{DNA damage-induced repression of telomerase activity correlates with TER2 induction}

Since a null mutation in TER2 does not affect telomere length homeostasis under standard growth conditions, we asked whether TER 2 modulates telomerase activity in response to genotoxic stress. We recently discovered that telomerase activity is inhibited in A. thaliana seedlings treated with the radiomimetic drug zeocin (Boltz et al. 2012). To further investigate how telomerase activity levels are affected by DNA damage, 7-d-old wild-type seedlings were transferred to liquid culture containing $20 \mu \mathrm{M}$ zeocin, and Q-TRAP was performed at different time intervals beginning $30 \mathrm{~min}$ after transfer to drug. As expected for the Arabidopsis DDR (Fulcher and Sablowski 2009), this regime elicited a strong induction of BRCA1 mRNA within $4 \mathrm{~h}$ of drug treatment (Fig. 4A). In addition,

A

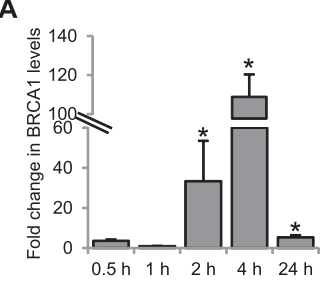

B

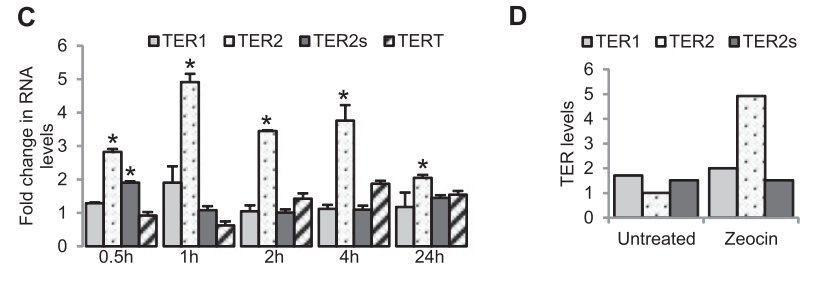

$E$

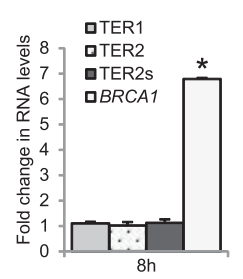

$\mathbf{F}$

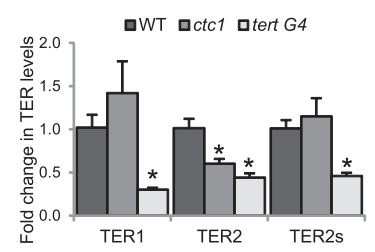

Figure 4. TER2 is induced in response to DNA damage. $(A)$ Results of qRT-PCR analysis for BRCA1 mRNA following zeocin treatment. Seven-day-old wild-type seedlings were treated for the time points indicated. $(B)$ Q-TRAP results for seedlings incubated in water (no treatment [nt]) or zeocin (zeo). Fold change in telomerase activity is indicated relative to no treatment. (C) qRT-PCR analysis of TER isoforms and TERT mRNA after zeocin treatment at the time points indicated. RNA levels are shown relative to untreated wild-type samples from the same time point. $(D)$ TER levels in wild-type seedlings with or without zeocin treatment are plotted. Data were normalized to the TER2 untreated. (E) qRT-PCR analysis of the TER isoforms and BRCA1 mRNA after $8 \mathrm{~h}$ in HU. $(F)$ qRTPCR for TER in wild type and ctc1 and G4 tert mutants are shown. RNA levels are plotted relative to wild type. Significance for all experiments was calculated relative to untreated at each time point using a Student's $t$-test; $\left(^{\star}\right) P \leq 0.05$. staining of the root apical meristem (RAM) with propidium iodide (PI), a membrane-impermeable dye that only enters dead cells, revealed stem cell death (see Fig. 5B), consistent with DDR activation (Fulcher and Sablowski 2009; Furukawa et al. 2010). A statistically significant decrease in telomerase activity was observed in seedlings after $30 \mathrm{~min}$ in zeocin; enzyme activity declined by $\sim 50 \%$ relative to untreated samples (Fig. 4B). A similar response was obtained for all of the time points tested. Telomerase activity was also significantly reduced in zeocin-treated flowers relative to controls, indicating that this response occurs in both vegetative and reproductive organs (Supplemental Fig. S4A).

To ask whether the decline in telomerase activity correlated with a change in the steady-state level of TER, qRT-PCR was conducted. The abundance of TERT mRNA and TER1 was largely unaffected by zeocin treatment (Fig. 4C). In contrast, zeocin triggered a threefold increase in TER2 after $30 \mathrm{~min}$ and a peak consisting of a fivefold increase after $1 \mathrm{~h}$, well before the peak of BRCAl mRNA accumulation (Fig. 4C). Although TER2 $\mathrm{s}$ levels increased twofold after $30 \mathrm{~min}$ in zeocin, this response was transient and not observed with longer treatment. Thus, the induction of TER2 did not result in a concomitant increase in TER $2_{\mathrm{s}}$. Within $1 \mathrm{~h}$ of zeocin treatment, TER 2 became the most abundant TER isoform (Fig. 4D).

We next asked whether the rapid induction of TER2 is specifically triggered by DSBs or reflects a more general response to DNA damage. Wild-type seedlings were treated with $10 \mathrm{mM}$ hydroxyurea $(\mathrm{HU})$ to induce replication fork stalling. After $8 \mathrm{~h}$, BRCA1 mRNA was induced sevenfold, analogous to the 1- to 2-h zeocin time points (Fig. 4E). However, in contrast to zeocin, HU did not alter the level of any of the TER isoforms (Fig. 4E). Moreover, Q-TRAP revealed no significant change in telomerase activity under these conditions (Supplemental Fig. S4B). In Arabidopsis, telomerase activity is wild type in G1 atr mutants but then declines dramatically in later generations (Boltz et al. 2012). The mechanism underlying this repression is unknown but may reflect accumulating replication stress. As with HU treatment, TER2 was not induced in G1 or third-generation (G3) atr mutants (Supplemental Fig. S4C).

Finally, we asked whether TER2 induction is associated with telomere dysfunction. TER2 was not induced by loss of CTC1, a core component of the CST complex (Surovtseva et al. 2009), or the prolonged absence of telomerase in fourthgeneration (G4) tert mutants (Fig. 4F), although both mutations activate DDR (Fig. 5A; Boltz et al. 2012). In plants lacking TERT, all three TER isoforms were reduced, suggesting that TERT promotes their stability. Notably, TER2, but not TER1 or TER $2_{S}$, declined significantly in ctc1 mutants (Fig. 4F). Taken together, the data indicate that increased accumulation of TER 2 reflects an early and specific response to DSBs at internal sites within the genome.

DNA damage-induced repression of telomerase activity is dependent on TER2

We investigated the role of TER2 in zeocin-induced telomerase inhibition by monitoring DDR transcript 
A

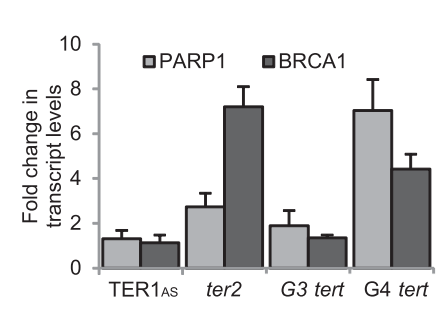

C

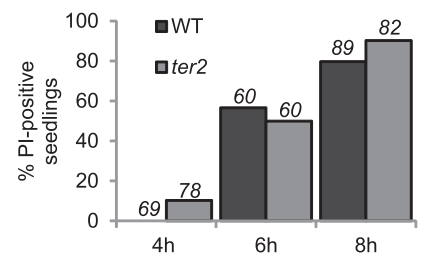

B

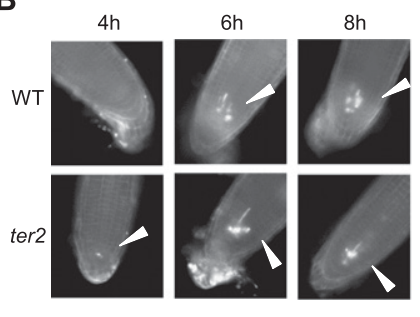

D

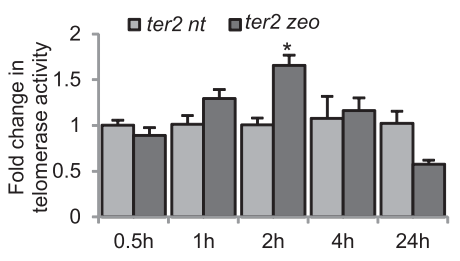

Figure 5. TER2 is required for DNA damage-induced repression of telomerase activity. (A) qRT-PCR results for BRCA1 and PARP1 mRNAs in the genetic backgrounds indicated. Fold change is shown relative to untreated seedlings. $(B)$ Representative images of the RAM in 5-d-old seedlings stained with PI after zeocin treatment. Arrowheads denote PI-positive stem cells. (Right) A schematic diagram of the RAM is shown with stem and progenitor cells (in gray) surrounding the quiescent center (in white). (C) Percentage of seedlings containing a PI-stained stem cell. Results are for three independent experiments. The number of seedlings examined is indicated above each bar in italics. (D) Q-TRAP results for zeocin-treated and untreated ter2 seedlings. $n \geq 4$ for each time point in both qRT-PCR and Q-TRAP experiments. levels and the viability of the RAM in 7-d-old ter2-1 seedlings. Unexpectedly, even in the absence of drug, BRCA1 and, to a lesser extent, PARP1 mRNAs were elevated in ter2-1 mutants (Fig. 5A), consistent with constitutive activation of DDR. As a control, we assessed PARP1 and BRCA1 mRNA levels in G3 and G4 tert mutants. G3 mutants showed little evidence of DDR, but both BRCA1 and PARP1 mRNAs were elevated in G4 tert mutants (Fig. 5A), consistent with impending telomere dysfunction (Riha et al. 2001). Despite the apparent constitutive activation of DDR in ter2-1 mutants, PI staining revealed that these seedlings were slightly more sensitive to DNA damage than wild type. After $4 \mathrm{~h}$ in zeocin, cell death was detected in the RAM of ter2-1 root tips but not in wild type (Fig. 5B,C). The response of ter2-1 mutants was earlier but not more robust than wild type. By $6 \mathrm{~h}$ in the drug, the same number of PI-stained cells was observed in both genetic backgrounds (Supplemental Fig. S5). These findings functionally link TER2 to DNA damage signaling.

In marked contrast to wild-type plants, ter2-1 mutant seedlings did not display a reduction in telomerase activity following zeocin treatment (Fig. 5D). Q-TRAP showed no statistical difference in enzyme activity in treated versus untreated ter2-1 seedlings after $1 \mathrm{~h}$ in the drug, and after $2 \mathrm{~h}$, telomerase activity increased compared with untreated controls (Fig. 5D). By $24 \mathrm{~h}$, telomerase activity decreased substantially in ter2-1 seedlings, likely reflecting massive stem cell death associated with protracted genotoxic stress. The failure to down-regulate telomerase activity in response to zeocin was also observed in ter2-1 flowers, although in this setting, the elevated levels of telomerase did not diminish even after $24 \mathrm{~h}$ in the drug (Supplemental Fig. S4A). Taken together, these data indicate that TER2 is a novel component of the DDR required for the immediate reduction in telomerase activity triggered by DSBs.

\section{Discussion}

Gene duplication is a major driving force for genomic diversity. Within the realm of telomere biology, core components of the vertebrate shelterin complex, TRF1/TRF2 and POT1a/POT1b, exemplify how gene duplication and neo-functionalization shape the interactions and regulation of chromosome ends (Linger and Price 2009). Critical components of telomerase have also been subjected to duplication and diversification. The ciliated protozoan Euplotes crassus harbors three divergent TERT genes that prompt a profound switch in telomerase behavior from an enzyme that acts promiscuously for DNTF to an enzyme that maintains telomere length homeostasis (Karamysheva et al. 2003). Here we describe another instance of neo-functionalization of a core telomerase subunit. In this case, TER gene duplication is linked to the emergence of alternative telomerase RNP complexes and a novel regulatory pathway that restrains enzyme activity in response to DNA damage.

\section{Three isoforms of TER assemble into distinct RNP complexes}

The three TER isoforms that we discovered in A. thaliana are unprecedented; all other organisms studied to date harbor a single TER gene. A. thaliana TER1 and TER2 are encoded by separate genetic loci (Cifuentes-Rojas et al. 2011), while TER $2_{S}$ is produced via splicing and $3^{\prime}$ end cleavage of TER2. Although a bona fide splicing reaction has not been described for other TER moieties, cleavage of the 3' end of S. pombe TER1 is required for telomerase function (Box et al. 2008). SpTER1 transcripts bearing a poly(A) tail can be detected in fission yeast (Box et al. 2008; Leonardi et al. 2008), but the 3' terminus of the RNA associated with active telomerase is formed by "slicing," a novel mechanism in which the spliceosome carries out only the first transesterification reaction (Leonardi et al. 2008). Unlike S. pombe TER, A. thaliana TER2 lacks canonical mRNA splicing signals and hence may be subjected to a different set of unconventional RNA processing reactions. Removal of the intervening sequence in TER2 occurs with high precision, leading to the juxtaposition of CR1 and CR2, the two domains that 
are conserved with TER 1 . In contrast, the TER $2_{S}$ molecules that we recovered had slightly different $3^{\prime}$ ends. Whether this heterogeneity reflects nucleolytic processing or alternative cleavage site selection is unknown. Intriguingly, the factors necessary for TER2 processing appear to be limiting in vivo and subject to environmental cues because increasing TER2 (by artificial overexpression or induction by DNA damage) does not lead to a parallel increase in TER $2_{S}$. Thus, the mechanism and regulation of TER2 processing warrant further investigation.

A neo-functionalization model for TER evolution is supported by the fact that Arabidopsis not only encodes multiple TER subunits, but also assembles TER2 and its processed product into alternative RNP complexes that are distinct from TER1 RNP (Fig. 6A). Both TER1 and TER2 associate with TERT and dyskerin, akin to the core human telomerase RNP (Cohen et al. 2007). However, TER2 interacts with $\mathrm{Ku}$, a protein complex not found in the TER1 RNP (Cifuentes-Rojas et al. 2011). Moreover, the POT1 paralogs POT1a and POT1b distribute to TER1 and TER2/TER2 $2_{S}$ complexes, respectively. Even though TER2 assembles into an enzymatically active particle in vivo, it does not significantly contribute to telomere maintenance. It is conceivable that TER2 RNP lacks a telomerase recruitment factor like Est1 from budding yeast (Evans and Lundblad 1999) to properly position the enzyme at the chromosome terminus. The TER1-associated factor POT1a is postulated to serve this function in Arabidopsis (Surovtseva et al. 2007). Our data indicate that TERT does not strongly associate with TER2 $\mathrm{S}$ in vivo, consistent with its low affinity for this TER isoform in vitro. Instead, TER $2_{S}$ accumulates into a subcomplex enriched for POT1b. Under standard growth conditions, TER $2_{\mathrm{S}}$ is as abundant in plants as the canonical telomerase RNA subunit TER1, arguing that this alternative TER makes a biologically significant contribution to telomere biology (see below).
TER2: a novel noncoding RNA induced in response to DSBS

Genetic analyses reveal that TER2 negatively regulates telomerase activity and, further, that this function is triggered by DNA damage. Within $30 \mathrm{~min}$ of zeocin treatment, well before the peak of BRCA1 mRNA induction, TER2 begins to accumulate, and telomerase activity declines. Although a $50 \%$ reduction in enzyme activity was measured, this value may be an underestimate of the response, since stem cell niches (the shoot and root apical meristems) where telomerase is most active make up only a tiny fraction of the seedling biomass. For similar reasons, the true extent of zeocinmediated TER2 induction may be much greater.

TER2 induction appears to be a specific response to DSBs. TER2 expression is unaffected by replication stress or telomere dysfunction, even though DDR is activated in both situations (Boltz et al. 2012; this study). Robust telomerase activity would in fact be advantageous in the latter setting, as it could delay the onset of catastrophic telomere failure. In contrast to TER2, the long noncoding RNA (lncRNA) derived from telomere transcription, TERRA, is induced in mammalian cells in response to telomere dysfunction (Caslini et al. 2009), where it is proposed to reinforce the heterochromatic character of the chromosome terminus (Luke and Lingner 2009). Thus, the induction of telomere-related lncRNAs as well as the fate of telomerase may hinge on the chromosomal context in which a DDR is elicited.

Our data define TER2 as a new member of an expanding cadre of noncoding RNAs induced by DNA damage (Wouters et al. 2011). The expression, processing, and maturation of a variety of microRNAs are altered in response to DSBs in both plants and animals $(\mathrm{Hu}$ and Gatti 2011; Wei et al. 2012). Wang and Chang (2011) recently proposed four archetypes to describe the contributions of lncRNAs. Three of these may be instructive for

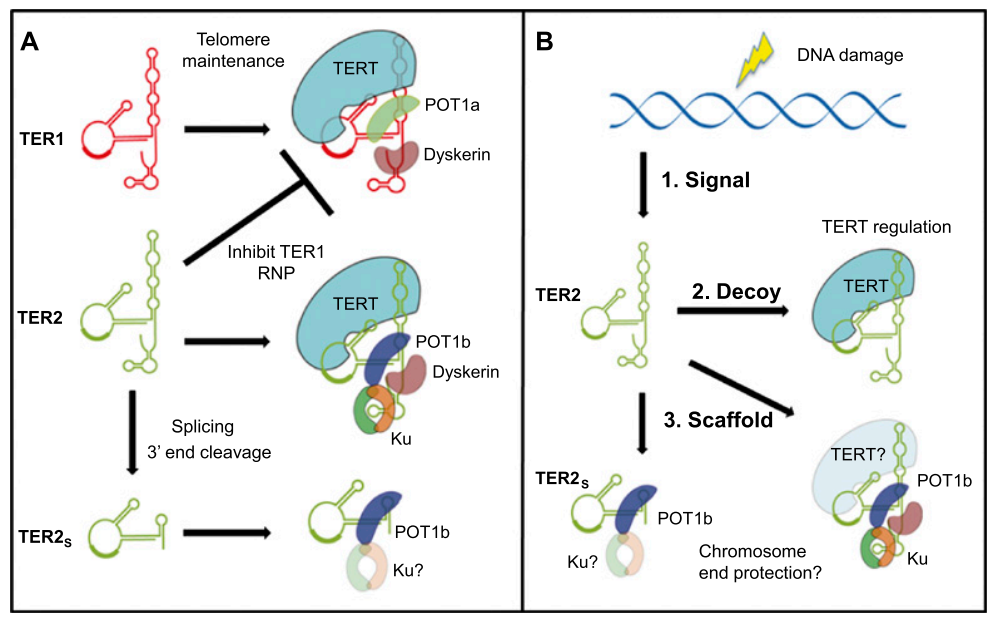
to DNA damage. (2) TER2 has a higher affinity for TERT than TER1 and may sequester TERT in a nonfunctional complex. (3) The association of POT1b and $\mathrm{Ku}$ with TER2/TER2 $\mathrm{S}$ may unite these protein factors at telomeres to promote chromosome end protection. See the text for details. TER2 is specifically and rapidly induced in response

Figure 6. Model for Arabidopsis TER2: its processing, protein-binding partners, and possible roles in telomere biology. (A) Arabidopsis harbors three distinct TER isoforms. TER 1 , the canonical TER, is responsible for telomere maintenance and associates with the RNP maturation complex dyskerin as well as POT1a, a positive regulator of telomerase function in vivo. TER 2 negatively regulates TER 1 function but does not substantially contribute to telomere maintenance. Like TER1, TER2 associates with TERT and dyskerin but also interacts with $\mathrm{Ku}$ and POT1b, accessory factors that are not enriched in TER1 RNP. TER2 is processed in vivo to generate TER2 $\mathrm{S}$. TER2 $S$ does not accumulate in an RNP with TERT or dyskerin, but rather forms a subcomplex containing POT1b and perhaps Ku. (B) Three potential modes of TER2/TER $2_{S}$ action based on the lncRNA archetypes described by Wang and Chang (2011). (1) 
TER2 (Fig. 6B). First, lncRNAs can behave as a molecular signal. Several lines of evidence indicate that TER2 acts as a specific biological marker for DNA damage in Arabidopsis. The induction of TER2 in response to DSBs parallels the transcriptional activation of the major DDR markers BRCA1 and PARP1. In addition, TER2 is functionally linked to DDR: DDR transcripts are constitutively expressed in ter2-1 mutants, and plants are more sensitive to DNA damage than wild type. DDR is activated in seeds as a normal part germination (Balestrazzi et al. 2011), and it is possible that ter2-1 mutants are particularly sensitive to the DNA damage associated with development. The net response to zeocin treatment in ter2-1 mutants is the same as in wild-type plants. Although ter2-1 mutants are capable of mounting a conventional DDR, they cannot down-regulate telomerase activity in response to DNA damage. Thus, TER2 not only heralds DNA damage, but also triggers the reduction in telomerase activity that occurs because of it. Considering the myriad mechanisms that restrict telomerase action at DSBs (Wong et al. 2002; Makovets and Blackburn. 2009; Zhang and Durocher 2010), it is likely that TER2 is only one of several genetic safeguards in Arabidopsis. Notably, TER 1 is embedded in the $5^{\prime}$ untranslated region (UTR) of one of two RAD52 orthologs in Arabidopsis (Samach et al. 2011). Whether this RNA contributes in some way to DDR is an open question.

A second lncRNA archetype is a decoy to sequester protein-binding partners (Wang and Chang 2011). Our data indicate that TER2 can sequester TERT in a nonproductive complex (Fig. 6B). We found that TERT preferentially associates with TER2 over TER1 in vivo, and overexpression of TER2 specifically inhibits TER1directed telomere repeat incorporation, leading to telomere shortening. Besides curtailing telomerase enzyme activity, TER2 also has the potential to hijack nontelomeric functions of TERT. For human TERT, these functions include stimulation of cell proliferation and repression of apoptosis (Cao et al. 2002; Sarin et al. 2005), activities that would ideally be constrained in response to DNA damage.

A third archetype for lncRNA is a scaffold to bring effector molecules together (Wang and Chang 2011). One interesting possibility is that TER2 and/or TER $2_{S}$ act as a scaffold for a telomere-capping RNP complex (Fig. 6B). Several studies in yeast and human cells point to a noncatalytic role for telomerase RNP in chromosome end protection (Zhu et al. 1999; Chan and Blackburn 2003; Hsu et al. 2007). Although TER2 RNP does not effectively maintain telomere repeats, it may engage the chromosome terminus, as evidenced by rare telomere repeat misincorporation events in plants overexpressing TER $2_{\mathrm{RSA}}$. Intriguingly, the two specific binding partners for TER2 and TER $2_{S}, \mathrm{Ku}$ and POT1b, are both implicated in chromosome end protection. In contrast to its paralog, POT1a, overexpression of the POT1b N terminus leads to dramatic telomere shortening and end-to-end chromosome fusions (Shakirov et al. 2005). Riha and colleagues (Kazda et al. 2012) recently demonstrated that Ku functions as a critical capping component for blunt-ended telomeres, which constitute $\sim 50 \%$ of the chromosome ends in Arabidopsis. Thus, TER2 and TER $2_{S}$ may promote genome integrity by uniting $\mathrm{Ku}$ and POT1b at natural blunt-ended telomeres or by physically blocking TER1 RNP from accessing DSBs. TER2 also has the potential to influence $\mathrm{Ku}$ in its conventional DNA repair capacity. Ku cannot bind DNA and RNA simultaneously (Pfingsten et al. 2012). Remarkably, Ku swaps its RNA-binding partner for DNA in response to DNA damage (Adelmant et al. 2012). Thus, dynamic interactions between $\mathrm{Ku}$ and TER2 may underlie an additional regulatory mechanism for DNA repair.

Unlike small regulatory RNAs, lncRNAs are very weakly conserved, tending to emerge quickly and evolve swiftly (Ponting et al. 2009). A survey of other members of the Brassicaceae family reveals surprisingly rapid evolution of the TER locus, including striking divergence within the telomere templating domain (Beilstein et al. 2012). Furthermore, although putative TER1 orthologs can readily be identified, TER2 counterparts have only been detected in $A$. thaliana. While it is possible that TER2 is a unique $A$. thaliana invention, none of the mechanisms for TER2 action outlined above require an intact telomere templating domain, a defining feature of TER. Thus, TER2-like regulatory molecules may well exist in other organisms, including mammals, where dysregulation of telomerase has dire consequences.

\section{Materials and methods}

\section{Plant materials and growth conditions}

Plants were grown on soil at $22^{\circ} \mathrm{C}$ under a 16 -h light/8-h dark photoperiod. For experiments with seedlings, seeds were sterilized in $50 \%$ bleach with $0.1 \%$ Triton X-100 and then plated on Murashige and Skoog (MS) medium with $0.7 \%-0.8 \%$ agar. Plates were kept for $2-4 \mathrm{~d}$ at $4{ }^{\circ} \mathrm{C}$ and then transferred to long-day conditions. The MM2d suspension cell culture line (Menges and Murray 2002) was used for all cell culture experiments. The mutant $A$. thaliana lines were ter2-1 and $35 S:: T E R 1_{A S}$ (Cifuentes-Rojas et al. 2011), tert (Fitzgerald et al. 1999), atr-2 (Culligan et al. 2004), and ctc1-1 (Surovtseva et al. 2009).

\section{Template mutation and plant transformation}

A PCR product containing the RSA template mutation was generated with TER $2_{\mathrm{RSA}}$ fwd and TER2end reverse primers. Supplemental Table S1 lists these and all other primer sequences for this study. The mutation was confirmed by sequencing. TER2 $2_{\text {RSA }}$ was cloned into the destination vector $\mathrm{pB} 7 \mathrm{WG} 2$ and transformed into ter2-1 homozygous mutants as described (Surovtseva et al. 2007). After transformation, seeds were selected in MS agar containing $50 \mu \mathrm{g} / \mathrm{mL}$ kanamycin.

\section{TRF analysis and TRAP and PETRA assays}

TRF, TRAP, and Q-TRAP assays were performed as described (Shakirov et al. 2005; Kannan et al. 2008). For TRAP reactions with mutant $35 \mathrm{~S}:$ :TER2 $2_{\text {RSA }}$ lines, a specific mutant reverse primer $\left(\right.$ TER2 $2_{\text {RSA }}$ TRAP) was used. PETRA was performed on either wild-type or $35 \mathrm{~S}::$ TER $2_{\mathrm{RSA}}$ lines as described (Heacock et al. 2007). The PETRA-T reaction used either the standard PETRA-T primer or a modified version (TER $2_{\text {RSA }}$ PETRA-T) to 
amplify repeats generated from TER $2_{\mathrm{RSA}}$. The PETRA-A reaction used the standard PETRA-A primer and 1L chromosome arm primer. For sequencing, PETRA products were cloned into the pDRIVE vector (Qiagen).

\section{RNA analysis}

Total RNA was extracted using Tri reagent (Sigma), and cDNA was synthesized using SuperScript III reverse transcriptase (Invitrogen) as described (Cifuentes-Rojas et al. 2011). For the DNA damage-related and TER2 mapping experiments, RNA was extracted using the EZNA plant RNA kit (Omega Bio-tek). cDNA was generated by using 1-2 $\mu \mathrm{g}$ of total RNA with the qScript cDNA supermix (Quanta Biosciences). To map the 3 ' end and splice junction in TER $2_{s}$, we used the protocol by Lu et al. (2007) with some modifications. Twenty micrograms of purified RNA was separated on a $10 \%$ polyacrylamide/urea gel. Using in vitro transcribed TER $2_{\mathrm{S}}$ as a marker, a gel slice corresponding to 200-300 nt was cut from the gel and pulverized with a pestle, $500 \mu \mathrm{L}$ of $0.3 \mathrm{M} \mathrm{NaCl}$ was added, and the sample was incubated overnight at room temperature. Ethanol precipitation followed. Samples were resuspended in a final volume of $10 \mu \mathrm{L}$. A PAGEpurified 3' RNA adaptor (Dharmacon) was ligated in a $10-\mu \mathrm{L}$ reaction consisting of $5 \mu \mathrm{L}$ of purified RNA, $2 \mu \mathrm{L}$ of $3^{\prime}$ RNA adaptor $(20 \mu \mathrm{M}), 1 \mu \mathrm{L}$ of $10 \times$ RNA ligase buffer, and $2 \mu \mathrm{L}$ of T4 RNA ligase (Ambion). The ligation reaction was incubated for $6 \mathrm{~h}$ at room temperature, followed by gel purification. cDNA was generated from the purified RNA, and then $3^{\prime}$-tagged TER $2_{S}$ was amplified using primers TER2 forward and $3^{\prime}$-linker reverse. PCR products were cloned into the pDRIVE vector (Qiagen) and sequenced.

Primer extension and Northern blotting were carried out as described (Cifuentes-Rojas et al. 2011). For Northern blotting, the probe was a pool of $5^{\prime}$ end ${ }^{32} \mathrm{P}$-ATP-labeled oligo CR1 and CR2 regions of the TERs. qRT-PCR was run as described (Cifuentes-Rojas et al. 2011; Boltz et al. 2012) using SYBR Green master mix (New England Biolabs and Bio-Rad). GAPDH, actin, and U6 served as reference genes. The LinReg PCR software (Ruijter et al. 2009) was used to calculate primer efficiencies and adjust expression levels accordingly.

Immunoprecipitation, RNA-protein-binding assays, and in vitro telomerase reconstitution

Filter-binding assays, electrophoretic mobility shift assays, and in vitro telomerase reconstitution assays were performed as described (Cifuentes-Rojas et al. 2011) using T7-tagged proteins expressed from pET28a vectors using RRL (T7 TnT-Coupled Reticulocyte Lysate System; Promega) and in vitro transcribed RNA. For in vitro co-IP experiments, either recombinant proteins were coexpressed with TER or TER was expressed separately. After immunoprecipitation, RNA was extracted, and RT-PCR was performed. Immunoprecipitation of Arabidopsis cell culture, including the antibodies used, was conducted as described (Cifuentes-Rojas et al. 2011).

\section{DNA damage treatments and assays}

Arabidopsis seedlings (5-7 d old) were gently removed from MS plates and incubated in liquid MS medium supplemented with $20 \mu \mathrm{M}$ zeocin (Invitrogen) or $10 \mathrm{mM} \mathrm{HU}$ (Sigma) according to Adachi et al. (2011). Seedlings were kept in the dark with gentle agitation for $0.5-24 \mathrm{~h}$. Inflorescences were removed from flowers and treated in the same manner. Multiple seedlings were combined for either RNA extraction or protein extraction (for Q-TRAP). Each combined sample was counted as one biological replicate. PI staining of seedling root tips was conducted as described (Boltz et al. 2012) with the following modification: On day 4 in the light, seedlings were gently removed from the agar, transferred to liquid MS, and slowly shaken overnight in constant light. On day 5 in the light, zeocin was added to the MS.

\section{Acknowledgments}

We thank Dudy Tzfati, Feng Qiao, Jeff Kapler, and members of the Shippen laboratory for helpful comments throughout the course of this study. This work was supported by NIH (GM-065383) and NSF (MCB-1052018) to D.E.S.

\section{References}

Adachi S, Minamisawa K, Okushima Y, Inagaki S, Yoshiyama K, Kondou Y, Kaminuma E, Kawashima M, Toyoda T, Matsui $M$, et al. 2011. Programmed induction of endoreduplication by DNA double-strand breaks in Arabidopsis. Proc Natl Acad Sci 108: 10004-10009.

Adelmant G, Calkins AS, Garg BK, Card JD, Askenazi M, Miron A, Sobhian B, Zhang Y, Nakatani Y, Silver PA, et al. 2012. DNA ends alter the molecular composition and localization of ku multicomponent complexes. Mol Cell Proteomics 11: 411-421.

Artandi SE, DePinho RA. 2010. Telomeres and telomerase in cancer. Carcinogenesis 31: 9-18.

Balestrazzi A, Confalonieri M, Macovei A, Dona M, Carbonera D. 2011. Genotoxic stress and DNA repair in plants: Emerging functions and tools for improving crop productivity. Plant Cell Rep 30: 287-295.

Baumann P, Price C. 2010. Pot1 and telomere maintenance. FEBS Lett 584: 3779-3784.

Beilstein MA, Brinegar AE, Shippen DE. 2012. Evolution of the Arabidopsis telomerase RNA. Front Genet 3: 188. doi: 10.3389/fncom.04.2012.

Boltz KA, Leehy K, Song X, Nelson AD, Shippen DE. 2012. ATR cooperates with CTC1 and STN1 to maintain telomeres and genome integrity in Arabidopsis. Mol Biol Cell 23: 15581568.

Boule JB, Vega LR, Zakian VA. 2005. The yeast Piflp helicase removes telomerase from telomeric DNA. Nature 438: 57-61.

Boulton SJ, Jackson SP. 1998. Components of the Ku-dependent non-homologous end-joining pathway are involved in telomeric length maintenance and telomeric silencing. $E M B O J$ 17: 1819-1828.

Box JA, Bunch JT, Zappulla DC, Glynn EF, Baumann P. 2008. A flexible template boundary element in the RNA subunit of fission yeast telomerase. J Biol Chem 283: 24224-24233.

Cao Y, Li H, Deb S, Liu JP. 2002. TERT regulates cell survival independent of telomerase enzymatic activity. Oncogene 21: 3130-3138.

Caslini C, Connelly JA, Serna A, Broccoli D, Hess JL. 2009. MLL associates with telomeres and regulates telomeric repeatcontaining RNA transcription. Mol Cell Biol 29: 4519-4526.

Chan SW, Blackburn EH. 2003. Telomerase and ATM/Tellp protect telomeres from nonhomologous end joining. Mol Cell 11: 1379-1387.

Cifuentes-Rojas C, Shippen DE. 2012. Telomerase regulation. Mutat Res 730: 20-27.

Cifuentes-Rojas C, Kannan K, Tseng L, Shippen DE. 2011. Two RNA subunits and POTla are components of Arabidopsis telomerase. Proc Natl Acad Sci 108: 73-78.

Cohen SB, Graham ME, Lovrecz GO, Bache N, Robinson PJ, Reddel RR. 2007. Protein composition of catalytically active 
human telomerase from immortal cells. Science 315: 18501853.

Culligan K, Tissier A, Britt A. 2004. ATR regulates a G2-phase cell cycle checkpoint in Arabidopsis thaliana. Plant Cell 16: 1091-1104.

Egan ED, Collins K. 2012. Biogenesis of telomerase ribonucleoproteins. RNA 18: 1747-1759.

Evans SK, Lundblad V. 1999. Est1 and Cdc13 as comediators of telomerase access. Science 286: 117-120.

Fitzgerald MS, Riha K, Gao F, Ren S, McKnight TD, Shippen DE. 1999. Disruption of the telomerase catalytic subunit gene from Arabidopsis inactivates telomerase and leads to a slow loss of telomeric DNA. Proc Natl Acad Sci 96: 14813-14818.

Flint J, Craddock CF, Villegas A, Bentley DP, Williams HJ, Galanello R, Cao A, Wood WG, Ayyub H, Higgs DR. 1994. Healing of broken human chromosomes by the addition of telomeric repeats. Am J Hum Genet 55: 505-512.

Fulcher N, Sablowski R. 2009. Hypersensitivity to DNA damage in plant stem cell niches. Proc Natl Acad Sci 106: 20984 20988.

Furukawa T, Curtis MJ, Tominey CM, Duong YH, Wilcox BW, Aggoune D, Hays JB, Britt AB. 2010. A shared DNA-damageresponse pathway for induction of stem-cell death by UVB and $\gamma$ irradiation. DNA Repair (Amst) 9: 940-948.

Hanish JP, Yanowitz JL, de Lange T. 1994. Stringent sequence requirements for the formation of human telomeres. Proc Nat1 Acad Sci 91: 8861-8865.

Heacock ML, Idol RA, Friesner JD, Britt AB, Shippen DE. 2007. Telomere dynamics and fusion of critically shortened telomeres in plants lacking DNA ligase IV. Nucleic Acids Res 35: 6490-6500.

Hsu M, McEachern MJ, Dandjinou AT, Tzfati Y, Orr E, Blackburn EH, Lue NF. 2007. Telomerase core components protect Candida telomeres from aberrant overhang accumulation. Proc Natl Acad Sci 104: 11682-11687.

Hu H, Gatti RA. 2011. MicroRNAs: New players in the DNA damage response. J Mol Cell Biol 3: 151-158.

Kannan K, Nelson AD, Shippen DE. 2008. Dyskerin is a component of the Arabidopsis telomerase RNP required for telomere maintenance. Mol Cell Biol 28: 2332-2341.

Karamysheva Z, Wang L, Shrode T, Bednenko J, Hurley LA, Shippen DE. 2003. Developmentally programmed gene elimination in Euplotes crassus facilitates a switch in the telomerase catalytic subunit. Cell 113: 565-576.

Karamysheva ZN, Surovtseva YV, Vespa L, Shakirov EV, Shippen DE. 2004. A C-terminal Myb extension domain defines a novel family of double-strand telomeric DNA-binding proteins in Arabidopsis. J Biol Chem 279: 47799-47807.

Kazda A, Zellinger B, Rossler M, Derboven E, Kusenda B, Riha K. 2012. Chromosome end protection by blunt-ended telomeres. Genes Dev 26: 1703-1713.

Kharbanda S, Kumar V, Dhar S, Pandey P, Chen C, Majumder P, Yuan ZM, Whang Y, Strauss W, Pandita TK, et al. 2000. Regulation of the hTERT telomerase catalytic subunit by the c-Abl tyrosine kinase. Curr Biol 10: 568-575.

Leonardi J, Box JA, Bunch JT, Baumann P. 2008. TER1, the RNA subunit of fission yeast telomerase. Nat Struct Mol Biol 15: 26-33.

Linger BR, Price CM. 2009. Conservation of telomere protein complexes: Shuffling through evolution. Crit Rev Biochem Mol Biol 44: 434-446.

Lu C, Meyers BC, Green PJ. 2007. Construction of small RNA cDNA libraries for deep sequencing. Methods 43: 110-117.

Luke B, Lingner J. 2009. TERRA: Telomeric repeat-containing RNA. EMBO J 28: 2503-2510.
Makovets S, Blackburn EH. 2009. DNA damage signalling prevents deleterious telomere addition at DNA breaks. Nat Cell Biol 11: 1383-1386.

Menges M, Murray JA. 2002. Synchronous Arabidopsis suspension cultures for analysis of cell cycle gene activity. Plant $J$ 30: $203-212$

Mitchell JR, Collins K. 2000. Human telomerase activation requires two independent interactions between telomerase RNA and telomerase reverse transcriptase. Mol Cell 6: 361371.

Pennock E, Buckley K, Lundblad V. 2001. Cdc13 delivers separate complexes to the telomere for end protection and replication. Cell 104: 387-396.

Pfingsten JS, Goodrich KJ, Taabazuing C, Ouenzar F, Chartrand P, Cech TR. 2012. Mutually exclusive binding of telomerase RNA and DNA by Ku alters telomerase recruitment model. Cell 148: 922-932.

Ponting CP, Oliver PL, Reik W. 2009. Evolution and functions of long noncoding RNAs. Cell 136: 629-641.

Ren S, Johnston JS, Shippen DE, McKnight TD. 2004. TELOMERASE ACTIVATOR1 induces telomerase activity and potentiates responses to auxin in Arabidopsis. Plant Cell 16: 29102922.

Riha K, McKnight TD, Griffing LR, Shippen DE. 2001. Living with genome instability: Plant responses to telomere dysfunction. Science 291: 1797-1800.

Ruijter JM, Ramakers C, Hoogaars WM, Karlen Y, Bakker O, van den Hoff MJ, Moorman AF. 2009. Amplification efficiency: Linking baseline and bias in the analysis of quantitative PCR data. Nucleic Acids Res 37: e45. doi: 10.1093/nar/gkp045.

Samach A, Melamed-Bessudo C, Avivi-Ragolski N, Pietrokovski S, Levy AA. 2011. Identification of plant RAD52 homologs and characterization of the Arabidopsis thaliana RAD52like genes. Plant Cell 23: 4266-4279.

Sarin KY, Cheung P, Gilison D, Lee E, Tennen RI, Wang E, Artandi MK, Oro AE, Artandi SE. 2005. Conditional telomerase induction causes proliferation of hair follicle stem cells. Nature 436: 1048-1052.

Shakirov EV, Surovtseva YV, Osbun N, Shippen DE. 2005. The Arabidopsis Pot1 and Pot2 proteins function in telomere length homeostasis and chromosome end protection. Mol Cell Biol 25: 7725-7733.

Shakirov EV, McKnight TD, Shippen DE. 2009. POT1-independent single-strand telomeric DNA binding activities in Brassicaceae. Plant J 58: 1004-1015.

Surovtseva YV, Shakirov EV, Vespa L, Osbun N, Song X, Shippen DE. 2007. Arabidopsis POT1 associates with the telomerase $\mathrm{RNP}$ and is required for telomere maintenance. $E M B O J \mathbf{2 6 :}$ 3653-3661.

Surovtseva YV, Churikov D, Boltz KA, Song X, Lamb JC, Warrington R, Leehy $\mathrm{K}$, Heacock $\mathrm{M}$, Price CM, Shippen DE. 2009. Conserved telomere maintenance component 1 interacts with STN1 and maintains chromosome ends in higher eukaryotes. Mol Cell 36: 207-218.

Tang W, Kannan R, Blanchette M, Baumann P. 2012. Telomerase RNA biogenesis involves sequential binding by Sm and Lsm complexes. Nature 484: 260-264.

Tesmer VM, Ford LP, Holt SE, Frank BC, Yi X, Aisner DL, Ouellette M, Shay JW, Wright WE. 1999. Two inactive fragments of the integral RNA cooperate to assemble active telomerase with the human protein catalytic subunit (hTERT) in vitro. Mol Cell Biol 19: 6207-6216.

Wang KC, Chang HY. 2011. Molecular mechanisms of long noncoding RNAs. Mol Cell 43: 904-914.

Wei W, Ba Z, Gao M, Wu Y, Ma Y, Amiard S, White CI, Rendtlew Danielsen JM, Yang YG, Qi Y. 2012. A role for 
small RNAs in DNA double-strand break repair. Cell 149: 101-112.

Wong JM, Kusdra L, Collins K. 2002. Subnuclear shuttling of human telomerase induced by transformation and DNA damage. Nat Cell Biol 4: 731-736.

Wouters MD, van Gent DC, Hoeijmakers JH, Pothof J. 2011. MicroRNAs, the DNA damage response and cancer. Mutat Res 717: 54-66.

Yu GL, Bradley JD, Attardi LD, Blackburn EH. 1990. In vivo alteration of telomere sequences and senescence caused by mutated Tetrahymena telomerase RNAs. Nature 344: 126132.

Zappulla DC, Goodrich K, Cech TR. 2005. A miniature yeast telomerase RNA functions in vivo and reconstitutes activity in vitro. Nat Struct Mol Biol 12: 1072-1077.

Zhang W, Durocher D. 2010. De novo telomere formation is suppressed by the Mec1-dependent inhibition of $\mathrm{Cdc13}$ accumulation at DNA breaks. Genes Dev 24: 502-515.

Zhu J, Wang H, Bishop JM, Blackburn EH. 1999. Telomerase extends the lifespan of virus-transformed human cells without net telomere lengthening. Proc Natl Acad Sci 96: 37233728. 


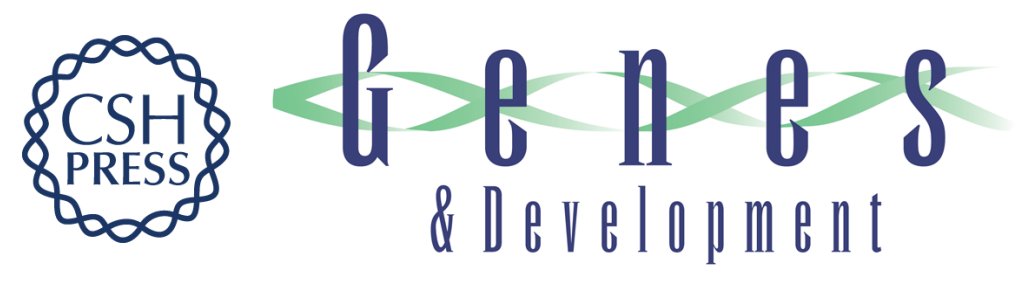

\section{An alternative telomerase RNA in Arabidopsis modulates enzyme activity in response to DNA damage}

Catherine Cifuentes-Rojas, Andrew D.L. Nelson, Kara A. Boltz, et al.

Genes Dev. 2012, 26: originally published online October 29, 2012

Access the most recent version at doi:10.1101/gad.202960.112

\section{Supplemental http://genesdev.cshlp.org/content/suppl/2012/10/24/gad.202960.112.DC1 Material}

References This article cites 61 articles, 25 of which can be accessed free at: http://genesdev.cshlp.org/content/26/22/2512.full.html\#ref-list-1

\section{License}

Email Alerting

Service

Receive free email alerts when new articles cite this article - sign up in the box at the top right corner of the article or click here.

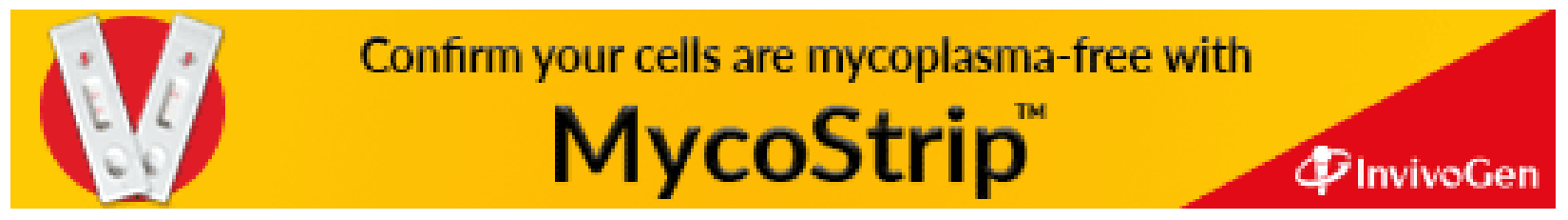

